\title{
Discharge Needs of Patients after Total Hip Arthroplasty
}

\author{
EMAN M. HOSNY, M.Sc.; BASSAMAT O. AHMED, D.N.Sc. and AMEL G. ABD EL-NABY, D.N.Sc. \\ The Department of Medical Surgical Nursing, Faculty of Nursing, Cairo University
}

\begin{abstract}
Background: Discharge needs are known to be common problems for total hip arthroplasty (THA) patients due to surgical and technological developments of arthroplasty, treatment procedures, and reducing the duration of hospitalization. Hence, nurses play an important role in assessment of discharge needs of patients following THA.
\end{abstract}

Aim of the Study: Is to explore discharge needs of patients after total hip arthroplasty.

Material and Methods: Convenient sample of all male and female patients scheduled to undergo THA, above 50 years, performing the surgery for the first time, having hip osteoarthritis. Data was collected using the following two tools: (a) Demographic and Medical Background Information Form, and (b) Arthroplasty Discharge Needs Assessment Tool (ADNA).

Results: The majority of sample aged between 51 to 70 years with a mean of $60.6 \pm 6.7$. Moreover, the majority of participants were females and married with a percentage of $58.3 \%$ and $86.7 \%$ respectively. Before discharge and two weeks after being discharged, all the participants expressed their unsatisfactory level of information in almost all categories of ADNA with the exception of home setup category. Consequently the overall ADNA scores prevail unsatisfactory.

Conclusion: The study concluded that, the studied subjects had unmet needs following THA before discharge and two weeks after being discharged.

Implications: Significant implication involves the need for further collaboration between health care providers and patients related to the kind and amount of information needed by hip arthroplasty patients especially after being discharged from hospital.

Recommendation: Longitudinal study should be designed to determine the long term needs for this group of patients over a long period of time.

Key Words: Total hip arthroplasty - Osteoarthritis - Discharge needs.

Correspondence to: Dr. Eman M. Hosny, The Department of Medical Surgical Nursing, Faculty of Nursing, Cairo University

\section{Introduction}

MUSCULOSKELETAL disorders have been identified as a major health problem affecting more than 1.7 billion people worldwide and have the fourth greatest impact on the overall health of the world population, considering both death and disability [1]

Osteoarthritis (OA) is one of the most common musculoskeletal disorders. It is a progressive degenerative joint disease which is responsible for significant disability in over 43 million people worldwide, 27 million of whom are 60 years of age or older [2], World Health Organization (WHO) estimated that the Prevalence of OA in the World was 151.4 million with an average estimation of about 30 million Americans currently affected by this disease [3]. In Egypt, more than five million people have osteoarthritis [4].

Hip osteoarthritis represents a major cause of disability especially in elderly people as it often causes prolonged suffering and serious disabilities, therefore, it is associated with a large societal and economic burden [5]. The management of hip osteoarthritis frequently involves the use of analgesics, walking aids, and physical therapy, however, total hip arthroplasty (THA) remains the gold standard treatment for moderate or severe hip osteoarthritis [6].

Total hip arthroplasty is one of the most effluent joint arthroplasty surgeries, and has become one of the most successful innovations in modern medicine [7]. The Procedure includes the surgical replacement of all, or part, of the hip joint with an artificial device. In fact, in total hip arthroplasty, the worn articular surfaces of the femur and the acetabulum are removed and replaced with artificial components $[\mathbf{8}]$. This operation considerably relieves both pain and functional disability experi- 
enced by patients suffering from hip osteoarthritis, thereby improving their quality of life [7].

Planning for hospital discharge is a core nursing task, health care providers especially nurses have a significant role to play in assessment and identification of patients' needs in general and patients' discharge needs in particular to help in coping with the current condition, as well as to prepare for discharge so that the patients can manage their care at home and safely resume activities [9].

Arthroplasty is followed by a period of postoperative recovery. During recent years, medical advances, new approaches to care and a policy to reduce costs have resulted in shorter hospital stays after hip arthroplasty, from 6-10 to 3-5 days lead to much of the postoperative care and monitoring have to be carried out at home by patients and their families [10]. This can be problematic and represent a major challenge for nurses to identify THA patients' unmet discharge needs and prepare for effective discharge plan.

Ensuring that patients 'discharge needs have been met prior to hospital discharge sets the stage for successful self-management of recovery at home [11]. In fact, unmet discharge needs may contribute to poor patient outcomes and readmission [12]. Yet assessment of patients' discharge needs is highly important for early identification of patients' unmet needs and intervention to enhance discharge readiness. Therefore, this study could be beneficial in providing health care providers especially nurses with data base regarding this area.

This data could be utilized by health care professionals in the provision of care for such group of patients. Furthermore, these research findings could be beneficial in maintaining cost-effective patient care as it might shorten hospital stay and protect patients against any life threatening complications. Also, it is hoped that, this effort will generate attention and motivation for further researches in this area.

\section{Aim of the study:}

The purpose of this study is to explore discharge needs of patients after total hip arthroplasty.

\section{Research question:}

To fulfill the aim of the current study the following research question is formulated: What are discharge needs for patients after total hip arthroplasty?

\section{Subject and Methods}

Research design:

A descriptive exploratory research design was utilized to achieve the purpose of this study.

Sample:

Convenient sample of all male and female patients scheduled to undergo total hip arthroplasty, aged over 50 years, performing the surgery for the first time, and diagnosed as having hip osteoarthritis admitted to the selected orthopedic departments in El-Manial University Hospital for consecutive six months lasted from August 2016 to February 2017.

\section{Tools for data collection:}

Data was collected using the following two tools which were developed by the research investigator after extensive literature/researches review: (a) Demographic and Medical Background Information Form, and (b) Arthroplasty Discharge Needs Assessment Tool (ADNA). The first tool consists of two sections; the first section includes 10 items about demographic data including: Age, gender, marital status, level of education, employment status, and place of residence...etc. While the second section consists of six items related to medical data such as: Current diagnosis, surgical history, current co morbidities, current medications, and family history of osteoarthritis and total hip arthroplasty.

On the other hand, Arthroplasty Discharge Needs Assessment Tool consists of fourteen categories with the total number of 55 indicators including: Movement and postures (8 indicators); pain management ( 3 indicators); medications ( 7 indicators); self care (4 indicators); dietary (4 indicators); physical therapy/exercises (7 indicators); complications (4 indicators); home set up (3 indicators); vocational (2 indicators); wound care(4 indicators); follow-up (3 indicators); social (2 indicators); emotional (1 indicator) and sexual and other needs ( 3 indicators).

\section{Scoring system:}

In each indicator, the fully known answers were scored (two), while partially known answers were scored (one) and wrong or unknown answers were scored (0). Both two and one scores are considered satisfactory for each indicator. The satisfactory level of categories and overall ADNA was considered $(70 \%)$.

\section{Tools Validity and Reliability:}

Content validity of the developed tools was established to identify the degree to which the used 
tools measures what it is supposed to measure. It is tested by subjecting the tools to a panel of three experts in the field of orthopedic medicine and medical surgical nursing. Each expert was asked to examine the tools for content coverage, clarity, and whether the included items are suitable to achieve the aim of the current study. Moreover, Cronbach's Alpha showed satisfactory level of reliability for Arthroplasty Discharge Needs Assessment Tool represented $=(0.86)$.

\section{Ethical consideration}

Primary approval was obtained from the Research and Ethics committee of Faculty of Nursing, Cairo University. Also an official permission was obtained from hospital/units administrators to conduct the study. Each participant was informed about the purpose of the study and its significance. The subjects were informed also that participation in the study is completely voluntary, as well as they have the right to withdraw from the study at any point without any penalty. Additionally, all participants were assured that their anonymity and confidentiality will be assured through coding the data. Moreover, participants were informed that the data will not be reused in another research without their permission to do so. Subjects who choose to participate were asked to sign the consent form. Last but not least approval obtained from Research and Ethics committee at the Faculty of Nursing, Cairo University right after completing of data.

\section{Pilot study:}

A pilot study was conducted on $10 \%$ of the expected sample (6 participants) to test feasibility of the study, as well as to examine issues related to the research design, sample size, data collection procedures, and data analysis approaches. Upon completion of the pilot study, the research investigator added two questions to Arthroplasty Discharge Needs Assessment Tool, as well as modified the language of some questions, hence, the pilot sample was excluded from the study sample.

\section{Procedure:}

Once official permission was granted to proceed with the proposed study, the investigator initiated data collection that lasted from August 2016 to February 2017. Names of potential patients who met criteria for possible inclusion were obtained daily from the head nurses of the concerned orthopedic department. Before the surgery, each potential patient was approached individually by the research investigator. At that time, the nature and the purpose of the study as well as the first follow-up visit schedule were explained; in addition to all other ethical considerations mentioned previously. Those who approved to participate in the study were asked to sign the consent form.

During initial interview and after the consent had been signed, the investigator completed the Demographic and Medical Background Information Form. This form was completed in about 10-15 minutes. At the day of discharge, the research investigator visited the patient once again in order to fill Arthropasty Discharge Needs Assessment Tool. This form was completed in about 20-30 minutes. In this session, the investigator reminded the patient about the first follow-up visit as per doctors' orders.

Two weeks later when the patients came back to the outpatient orthopedic clinic for removing the surgical sutures, the investigator visited the patient for the third time in order to fill the Arthroplasty Discharge Needs Assessment Tool for the second time. After completion of the pervious form, the investigator provided patients with sufficient information regarding their discharge needs as many of patients expressed interest to know more about how to fulfill needs after being discharged from the hospital.

\section{Statistical analyses:}

Upon completion of data collection, obtained data was tabulated, computed and analyzed using statistical package for the social sciences (SPSS) program version 20. Descriptive and Inferential statistics were utilized to analyze data pertinent to the study. Descriptive statistics included frequency, percentage distribution, mean and standard deviation. While, inferential statistics included $t$-test and F-test. A probability level of 0.05 was adopted as the level of significance.

\section{Results}

Based upon findings from Demographic and Medical Background Information Form, the majority of the studied subjects aged between 51 to 70 years with a mean of $60.6 \pm 6.7$ years, females and married (58.3\% and $86.7 \%$, respectively), housewives or unemployed $(56.7 \%, 35 \%$ respectively). Further two thirds of the studied subjects came from rural areas with income less than 1000 pounds ( $71 \%$ and $68 \%$ respectively). On the other hand, primary caregivers for the majority were sons and/or daughters (75\%).

With reference to medical data, the majority of the participants had co morbidities $(83.3 \%)$. Re- 
garding family history with osteoarthritis, more than two third (73.3\%) had negative family history. Moreover, the majority of the studied subjects $(96.7 \%)$ didn't have family history for hip arthroplasty.

Table (1) denoted that, concerning home setup needs, before discharge, the majority of participants $(71.7 \%)$ had satisfactory scores for the indicator called "someone for assistance at home" while after being discharged, all the participants (100\%) had satisfactory scores for all home setup indicators. It is apparent from the same table that, out of the three self care indicators, the only one indicator called "how can you to sit down and rise from toilet seat?" was in the satisfactory level for nearly half of the participants (48.3\%) two weeks after being discharged.
Table (2) depicted that, all pain management indicators were in the unsatisfactory level for the majority of the participants but the indicator namely "whether you will receive medications to mange possible pain at home?" was in the satisfactory level for $(91.7 \%)$ of the participants two weeks after being discharged.

In reference to the satisfactory level regarding categories and overall ADNA among the participants. It is apparent from data analysis that, before discharge from hospital, all participants expressed their unsatisfactory level of information in all categories; accordingly the overall ADNA satisfactory level prevails unsatisfactory. It is interested to note that, home set up category is the only category revealed to have satisfactory level by all participants two weeks after being discharged. Nevertheless, the level of unsatisfaction with the overall ADNA remains unchangeable.

Table (1): Frequency and percentage distribution of the satisfactory level as regards home setup and self care indicators among the studied participants $(\mathrm{n}=60)$.

\begin{tabular}{|c|c|c|c|c|c|c|c|c|}
\hline \multirow{3}{*}{ Categories / indicators } & \multicolumn{4}{|c|}{ Before discharge } & \multicolumn{4}{|c|}{2 weeks after being discharged } \\
\hline & \multicolumn{2}{|c|}{$\begin{array}{c}\text { Satisfactory } \\
(>=70 \%)\end{array}$} & \multicolumn{2}{|c|}{$\begin{array}{c}\text { Unsatisfactory } \\
(<70 \%)\end{array}$} & \multicolumn{2}{|c|}{$\begin{array}{c}\text { Satisfactory } \\
(>=70 \%)\end{array}$} & \multicolumn{2}{|c|}{$\begin{array}{c}\text { Unsatisfactory } \\
(<70 \%)\end{array}$} \\
\hline & No. & $\%$ & No. & $\%$ & No. & $\%$ & No. & $\%$ \\
\hline \multicolumn{9}{|l|}{ Home set up: } \\
\hline An elevated toilet seat? & 30 & 50.0 & 30 & 50.0 & 60 & 100.0 & 0 & 0.0 \\
\hline An Armrest chair? & 27 & 45.0 & 33 & 55.0 & 60 & 100.0 & 0 & 0.0 \\
\hline Someone to assist you at home? & 43 & 71.7 & 17 & 28.3 & 60 & 100.0 & 0 & 0.0 \\
\hline \multicolumn{9}{|l|}{ Self Care: } \\
\hline When will you be able to take a shower/bath? & 2 & 3.3 & 58 & 96.7 & 7 & 11.7 & 53 & 88.3 \\
\hline How can you take a shower/bath? & 2 & 3.3 & 58 & 96.7 & 8 & 13.3 & 52 & 86.7 \\
\hline How can you sit down and rise from the toilet? & 12 & 20.0 & 48 & 80.0 & 29 & 48.3 & 31 & 51.7 \\
\hline How can you put on socks, pants, stockings and shoes? & 6 & 10.0 & 54 & 90.0 & 11 & 18.4 & 49 & 81.7 \\
\hline
\end{tabular}

Table (2): Frequency and percentage distribution of the satisfactory level regarding pain management indicators among the studied participants $(n=60)$.

\begin{tabular}{|c|c|c|c|c|c|c|c|c|}
\hline \multirow{3}{*}{ Categories / indicators } & \multicolumn{4}{|c|}{ Before discharge } & \multicolumn{4}{|c|}{2 weeks after being discharged } \\
\hline & \multicolumn{2}{|c|}{$\begin{array}{l}\text { Satisfactory } \\
(>=70 \%)\end{array}$} & \multicolumn{2}{|c|}{$\begin{array}{l}\text { Unsatisfactory } \\
\qquad(<70 \%)\end{array}$} & \multicolumn{2}{|c|}{$\begin{array}{l}\text { Satisfactory } \\
(>=70 \%)\end{array}$} & \multicolumn{2}{|c|}{$\begin{array}{l}\text { Unsatisfactory } \\
\qquad(<70 \%)\end{array}$} \\
\hline & No. & $\%$ & No. & $\%$ & No. & $\%$ & No. & $\%$ \\
\hline \multicolumn{9}{|l|}{ Pain management: } \\
\hline What to do to alleviate the possible pain? & 1 & 1.7 & 59 & 98.3 & 1 & 1.7 & 59 & 98.3 \\
\hline The factors that may aggravate the pain? & 5 & 8.3 & 55 & 91.7 & 10 & 16.7 & 50 & 83.3 \\
\hline $\begin{array}{l}\text { Whether you will receive medications to manage } \\
\text { the possible pain? }\end{array}$ & 17 & 28.3 & 43 & 71.7 & 55 & 91.7 & 5 & 8.3 \\
\hline
\end{tabular}

Table (3) exhibited that, before discharge and two weeks after being discharged, the highest mean score was for home setup $(1.14 \pm 0.76 ; 2.00 \pm 0.00$ respectively), while the lowest mean score was for sexual and other needs $(0.02 \pm 0.12)$. The same table also denoted also that, statistically significance differences existed between the first assessment (before discharge) and the second assessment (two weeks after being discharged) regarding the following six categories: Home set up; self care; wound care; medications; 
pain management and follow-up $(t=8.75, p=.0001$; $t=3.12, p=.002 ; t=4.89, p=.0001 ; t=6.56, p=.0001$; $t=4.03, p=.0001 ; t=8.40, p=.0001$ respectively) as well as the overall ADNA $(t=6.80, p=.0001)$.

Table (3): Mean of differences of categories and overall ADNA before discharge and two weeks after being discharged ( $\mathrm{n}=60$ ).

\begin{tabular}{|c|c|c|c|c|}
\hline Category & $\begin{array}{l}\text { Before discharge } \\
(\mathrm{X} \pm \mathrm{SD})^{*}\end{array}$ & $\begin{array}{l}\text { Two weeks after discharge } \\
(\mathrm{X} \pm \mathrm{SD})\end{array}$ & $p$-value & $t$-value \\
\hline Home set up & $1.14 \pm 0.76$ & $2.00 \pm 0.00$ & 8.75 & $.0001 *$ \\
\hline Self Care & $0.11 \pm 0.25$ & $0.26 \pm 0.28$ & 3.12 & $.002 *$ \\
\hline Wound care & $0.33 \pm 0.35$ & $0.64 \pm 0.36$ & 4.89 & $.0001 *$ \\
\hline Movement and postures & $0.37 \pm 0.24$ & $0.44 \pm 0.29$ & 1.33 & .188 \\
\hline $\begin{array}{l}\text { Medications (related to } \\
\text { postoperative management) }\end{array}$ & $0.33 \pm 0.29$ & $0.59 \pm 0.06$ & 6.56 & $.0001 *$ \\
\hline Pain management & $0.22 \pm 0.33$ & $0.48 \pm 0.36$ & 4.03 & $.0001 *$ \\
\hline Physical therapy/Exercises & $0.15 \pm 0.24$ & $0.20 \pm 0.30$ & 0.97 & .332 \\
\hline Vocational & $0.38 \pm 0.76$ & $0.44 \pm 0.83$ & 0.46 & 646 \\
\hline Complications & $0.06 \pm 0.15$ & $0.07 \pm 0.20$ & 0.39 & .694 \\
\hline Diet information & $0.52 \pm 0.16$ & $0.57 \pm 0.21$ & 1.64 & .104 \\
\hline Follow-up & $0.21 \pm 0.43$ & $0.99 \pm 0.58$ & 8.40 & $.0001 *$ \\
\hline Social & $0.23 \pm 0.45$ & $0.31 \pm 0.52$ & 0.94 & .349 \\
\hline Emotional & $0.35 \pm 0.48$ & $0.42 \pm 0.50$ & 0.75 & .457 \\
\hline Sexual and other needs & $0.02 \pm 0.12$ & $0.02 \pm 0.12$ & 0.00 & 1.000 \\
\hline Total assessment & $0.30 \pm 0.17$ & $0.50 \pm 0.14$ & 6.80 & $.0001 *$ \\
\hline
\end{tabular}

\section{Discussion}

The current study documented that, the majority of the participants aged between 51 to 70 years with a mean of $60.6 \pm 6.7$. This finding is consistent with earlier findings presented in the literature $[9,13,14]$ who found that, the means of age of their studied patients were $(64.97 \pm 13.66 ; 62 \pm 7 ; 64 \pm 11$ \& 61.4 \pm 8.3 years respectively). These findings could be interpreted in the light of the fact that, the studied patients were diagnosed as having hip osteoarthritis and it was noted during review of the literature that advanced age is strongly correlates with the hip osteoarthritis [10].

Regarding gender, more than half of the participants were females. This finding is congruent with findings of previous studies presented in literature $[9,13,15]$ as they recognized that, the majority of their studied subjects were females. These finding could be explained in the light of the fact that, women have higher rates of osteoarthritis than men [16].

With reference to education level, more than half of the studied patients can't read or write. This finding is in harmony with El Shemey and Elsaay, [13] who indicated that the majority of their subjects were Illiterate. On the other hand, this finding doesn't agree with Johansson Stark et al., [10] who denoted that their hip arthroplasty patients had a high level of education. The finding that half of the participants in the current study can't read or write could be attributed to the fact that the majority of the participants came from rural areas, where illiteracy is a common problem. On the other hand, the disagreement with Johansson et al., [10] could be attributed to differences in sampling techniques utilized, setting and population.

Medical patient's background information in the current study included current co morbidities, medications and family history with osteoarthritis. The findings of the current study evidenced that, the majority of the participants have co morbidities, in form of diabetes; hypertension or both; though some other participants carried multiple co morbidities. These findings are consistent with earlier findings presented in literature $[\mathbf{1 7 , 1 8}]$ who denoted that the majority of their subjects had similar co morbidities. The factor that might contributed to this finding is the age of the studied subjects, lending support to this explanation what was reviewed in the literature that the prevalence of co morbidities increases with advancing age [19] Regarding family history with osteoarthritis, the majority of the participants have negative family history with osteoarthritis. This finding could be interpreted in the light of the fact that, the participants are old age and it was recognized from the literature that the aging process is considered the main contributed risk factor for hip osteoarthritis rather than the genetic or familial factors [10]

The current study demonstrated that, before discharge, all participants expressed their unsatis- 
factory level of information regarding all need categories of ADNA namely: Home set up; wound care; self care movement and postures; pain management; medications; physical therapy/exercises; complications; follow-up; dietary; vocational; social; emotional and sexual and other needs. While two weeks after being discharged, the unsatisfactory level regarding categories was unchangeable with the exception of home setup category. Nevertheless, the satisfactory level regarding the overall ADNA prevails unsatisfactory before discharge and two weeks after being discharged which indicates that all participants have unmet needs after arthroplasty before discharge and two weeks after being discharged. These findings are congruent with earlier findings presented in the literature $[9,15]$ they pointed out that their patients had high needs about medications, complications, activities of living, enhancing quality of life, skin care, community resources and follow-up. Furthermore, these findings are consistent with Omari, et al., [20] \& Temiz et al., [11] studies on the needs of different surgical patients groups and have produced similar results.

One possible factor for the above findings might be overwhelming health care providers with the number and complexity of the orthopedic patients. Another probably factor could be that short-stay tendency for arthroplasty patients in the hospital deters health care providers from spending enough time with patients to provide instructions toward their discharge needs. A third consideration might be that nature of the Egyptian culture and traditions which prevent many patients of expressing their needs thinking that if they have to know any information, it is the responsibility of the health care provider without asking. A fourth explanation could be that the patients were reluctant to ask questions because of an unfamiliar environment and lack of continuity in staff. A fifth consideration might be the incongruence between the patient's priorities and the healthcare provider's goals.

The current study highlighted that, statistically significant differences existed between the first assessment (before discharge) and the second assessment (two weeks after being discharged) regarding the following categories: Home set up, self care, wound care, medications, pain management and follow-up as well as the overall ADNA. In spite of presence of statistically significance differences, they remained in the unsatisfactory level. One possible explanation for these findings could be that when the patients being discharged and confronted with the home environment, independence in daily activities began to increase which push the participants to ask and know about their needs. Another explanation might be that interviewing the investigator for participants about their discharge needs arouse their interest to know more about how to fulfill needs. A third consideration might be simple instructions which the patients indicated they received from the health care providers at discharge.

\section{Conclusion:}

Patients following THA had unmet needs related to preventing potential complications, wound care, medication regimen, practicing proper movements and postures, proper self care practice, exercises program, pain management at home, follow-up schedule, nutrition regimen, resuming their intimate relationship, social and emotional supports. Nevertheless, These needs would be highly necessary for to THA patients to manage their care at home. Moreover there was statistically significant difference between the first assessment of discharge needs (before discharge) and the second assessment (two weeks after being discharged) but this difference didn't reach the satisfactory level.

\section{Implications:}

These findings imply:

- The necessity of designing, implementing and evaluation of collaborative, informative, a attractive discharge plan that address arthroplasty discharge needs, considering the health care providers time constraint and patient's short hospital stay.

- The need for further collaboration between health care providers and patients related to the kind and amount of information needed by hip arthroplasty patients especially after being discharged from hospital.

\section{Recommendations:}

- Replication of the study using a larger probability sample selected from different geographical areas in Egypt.

- Replication of the study matching subjects on the variable of gender.

- Longitudinal study should be designed to determine the long term needs these group of patients over a long period of time.

\section{References}

1- BHATIA D., BEJARANO T. and NOVO M.: Current interventions in the management of knee osteoarthritis. Journal of Pharmacy and Bioallied Sciences, 5 (1): 30, 2013.

2- PARVIZI J., KLATT B. and ADAMS C.S.: Essentials in total hip arthroplasty. Slack, pp. 39-45: 71, 2013. 
3- WHO. Disease incidences, Prevalence and disability. Available at http://www.who.int/healthinfo/ glbal_burden_ disease/GBD_report_2004update_part3.pdf.Retrieved on 23/12/2016.

4- MOHAMED N.A.: The Relation between Environmental Factors and Health Related Mobility Disability of Elderly Women with Osteoarthritis in Southern Egypt. Journal of American Science, 9 (5), 2013.

5- WOOLF A.D.: Global burden of osteoarthritis and musculoskeletal diseases. BMC Musculoskeletal Disorders, 16 (1): S3, 2015.

6- SALIH S. and HAMER A.: Hip and knee replacement. Surgery (Oxford), 31 (9), 482-4 Available at: www. . sciencedirect.com/science/journal/02639319/31/9, 2013.

7- MELLON S.J., LIDDLE A. D. and PANDIT H.: Hip replacement: Landmark surgery in modern medical history. Maturitas, 75 (3): 221-226, 2013.

8- British Orthopaedic Association. Primary Total Hip Replacement: A Guide to Best Practice, 2012.

9- S ENDIR M., BÜYÜKYıLMAZ F. and MU S OVI D.: Patients' Discharge Information Needs After Total Hip and Knee Arthroplasty: A Quasi Qualitative Pilot Study. Rehabilitation Nursing, 38 (5): 264-271, 2013.

10- JOHANSSON STARK Å., CHARALAMBOUS A., ISTOMINA N., SALANTERÄ S., SIGURDARDOTTIR, A.K., SOURTZI P. and BACHRACH_LINDSTRÖM M.: The quality of recovery on discharge from hospital, a comparison between patients undergoing hip and knee replacement-a European study. Journal of clinical nursing, 25 (17-18): 2489-2501, 2016

11- TEMIZ Z., OZTURK D., UGRAS G.A., OZTEKIN S.D. and SENGUL E.: Determination of Patient Learning Needs after Thyroidectomy. Asian Pacific Journal of Cancer Prevention, 17 (3): 1479-1483, 2016.

12- SOVANI S. and GROGAN S.: Osteoarthritis detection, pathophysiology and current/future treatment strategies. Orthopaedic Nursing, 23 (1): 25-36, 2013.

13-EL-SHEMEY B.A and ELSAAY A.E.: Efficacy of Implementing Nursing Care Protocol on Total Hip Replacement Patient's Outcome in Orthopedic Department at Tanta University Hospita, 2015.

14- DAYTON M.R., JUDD D.L., HOGAN C. A. and STEVENS-LAPSLEY J. E.: Performance-Based Versus SelfReported Outcomes Using the Hip Disability and Osteoarthritis Outcome Score After Total Hip Arthroplasty. American journal of physical medicine \& rehabilitation, 95 (2): 132-138, 2016.

15- MOHAMED S.J. and MECHESER A.E.: Assessment of Patients' Knowledge Toward Total Hip Replacement Home-Care. Iraqi Journal of Pharmaceutical Sciences (ISSN: 1683-3597, ESSN: 2521-3512), 21 (1): 39-45, 2017.

16-NEOGI T. and ZHANG Y.: Epidemiology of osteoarthritis. Rheumatic Disease Clinics of North America, 39 (1): 119, 2013.

17- DOWSEY M.M. and CHOONG P.F.: Predictors of pain and function following total joint replacement. INTECH Open Access Publisher, 2013.

18- KO Y.L., WU, H.F. and LIN P.C.: A survey o patients' quality of life and health-care needs prior to undergoing total joint replacement surgery. International journal of nursing practice, 19 (4): 415-422, 2013.

19- BJORGUL K., NOVICOFF W.M. and SALEH K.J.: Evaluating comorbidities in total hip and knee arthroplasty: Available instruments. Journal of orthopaedics and traumatology, 11 (4): 203-209, 2010.

20- OMARI F., AL-ZARU I. and AL-YOUSEF R.H.: Perceived learning needs of Syrian patients postcoronary artery bypass graft surgery. Journal of clinical nursing, 23 (1112): 1708-1717, 2014.

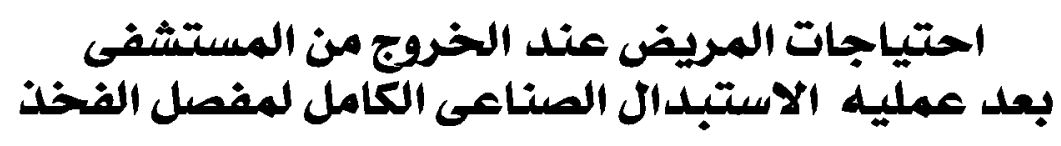

التهاب المفاصل من اكثر امراض العظام انتشارا في العالم وفى مصر خاصه ويعد الاستبدال الصناعى الكامل العلاج الامثل للمراحل

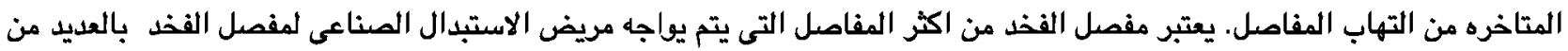

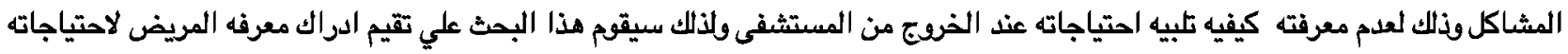

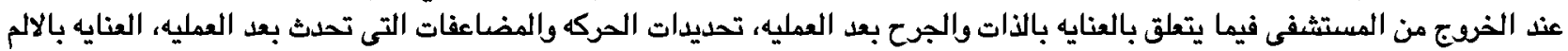

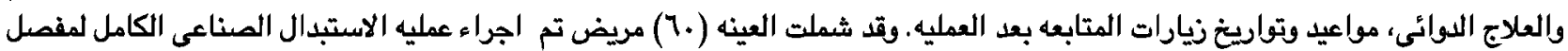
الفخذ لهم.

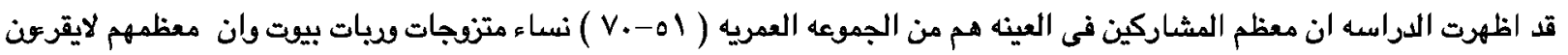

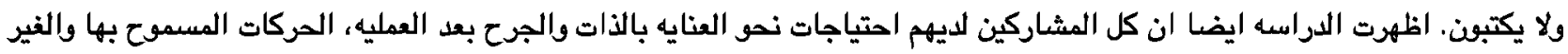

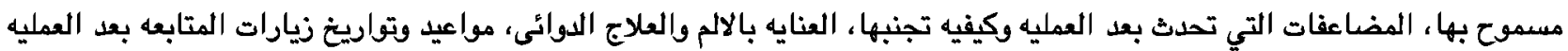

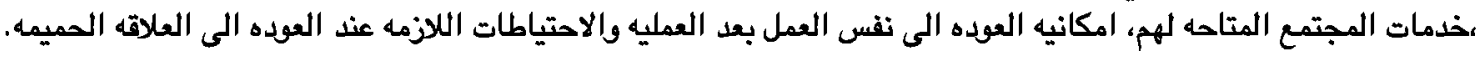

